CORRECTION

\title{
Correction to: Regional intra-arterial steroid treatment in 120 patients with steroid-resistant or -dependent GvHD
}

M. Y. Shapira, A. Klimov, V. Sheth, S. Grisariu, B. R. Avni, R. Or and A. I. Bloom

(c) The Author(s), under exclusive licence to Springer Nature Limited 2021

Bone Marrow Transplantation (2021) 56:3109; https://doi.org/10.1038/s41409-021-01504-6

Correction to: Bone Marrow Transplantation (2017) 52: 1416-1422; https://doi.org/10.1038/bmt.2017.120
In this article the author name $V$ Sheth was incorrectly written as S Vipul.

The original article has been corrected. 